\title{
Effect of estradiol on high glucose-induced osteoblast injury
}

\author{
GUANGRUN LI ${ }^{1 *}$, XIAOFENG JIANG ${ }^{2 *}$, LIPING LIU ${ }^{3}$, \\ XIAOYANG LIU ${ }^{1}$, HONGTAO LIU $^{1}$ and ZUOFU ZHANG ${ }^{2}$ \\ Departments of ${ }^{1}$ Spinal Surgery, ${ }^{2}$ Joint Surgery and ${ }^{3}$ Allergy, \\ Yantai Yuhuangding Hospital, Yantai, Shandong 264000, P.R. China
}

Received September 17, 2018; Accepted April 12, 2019

DOI: $10.3892 / \mathrm{mmr} .2019 .10552$

\begin{abstract}
Estradiol (E2) serves an important role in the changes of postmenopausal bone turnover rate and the development of osteoporosis. The present study aimed to investigate the effects of E2 on high glucose (HG)-induced osteoblast injury. Cell Counting Kit- 8 was used to determine cell viability. Reverse transcription-quantitative PCR (RT-qPCR) and western blotting was used to analyze the mRNA and protein expression levels of osteocalcin, Runt-related transcription factor 2 (Runx2), nuclear factor E2-related factor 2 (Nrf2) and heme oxygenase-1 (HO1). Flow cytometry was performed to analyze apoptosis. The results revealed that cell viability was lower in cells treated with $\mathrm{HG}(100,200$ or $300 \mathrm{mg} / \mathrm{dl})$ compared with the control group. Cell viability was decreased in cells treated with $200 \mathrm{mg} / \mathrm{dl} \mathrm{HG}$ on days 3,5 and 7. In addition, cell viability was increased by $0.1 \mu \mathrm{M} \mathrm{E} 2$. E2 with $\mathrm{HG}$ co-treatment increased cell viability, osteocalcin and Runx 2 mRNA expression levels and nuclear Nrf2 and HO1 protein expression levels compared with the HG-only group. All these changes, with the exception of Runx2, were reversed by silencing Nrf2 expression using small interfering (si)RNA (siNrf2). Additionally, apoptosis was reduced by E2 in HG-treated cells, which was reversed by siNrf2 transfection. These results demonstrated that E2 may prevent HG-induced osteoblast injury by activating $\mathrm{Nrf} 2 / \mathrm{HO} 1$ signaling pathways.
\end{abstract}

\section{Introduction}

In 2013, the prevalence of diabetes in Chinese adults was $11.6 \%$ (1). In patients with type 2 diabetes, approximately one-half to two-thirds of the cases are associated with a

Correspondence to: Dr Zuofu Zhang, Department of Joint Surgery, Yantai Yuhuangding Hospital, 20 East Yuhuangding Road, Zhifu, Yantai, Shandong 264000, P.R. China

E-mail: zuofuz_zhangzf@163.com

*Contributed equally

Key words: estradiol, high glucose, nuclear factor E2-related factor 2/heme oxygenase-1 signaling pathways, osteocalcin, Runt-related transcription factor 2 decrease in bone density, and one-third of the patients are diagnosed with osteoporosis (OP) (2). OP is a systemic bone disease characterized by bone density loss and bone microstructural changes, which results in increased bone fragility, decreased bone strength and increased risk of fracture $(3,4)$. Estradiol (E2) is a key factor in the development of OP, with evidence of significant bone loss in postmenopausal women $(5,6)$. Since the effect of estrogen on diabetes-related OP is not well understood, studies are necessary to provide new therapeutic strategies for clinical treatment.

E2 is one of the most potent estrogens (7), which serve important roles in human bone development and bone balance. Estrogen deficiency changes the activity of osteoclasts; as osteoclast function becomes relatively active, osteoblast function weakens (8). In addition, reduced apoptotic rate of osteoclasts indicates that bone formation rate is lower compared with bone resorption rate, which results in a decrease in bone minerals $(9,10)$.

Osteoblast genes are the main factors that promote the secretion and mineralization of the bone matrix (11). Runt-related transcription factor 2 (Runx2), which is a core binding factor, is one of the most important osteoblast-specific transcription factors. It is associated with extracellular osteogenic induction factors and intracellular factors, which also affect the signaling pathway of osteoblast functional differentiation (12). Osteocalcin is a bone-building compound expressed by osteoblasts that reflects the rate of bone turnover (13). Serum osteocalcin levels in patients with OP are significantly increased (14). Therefore, osteocalcin is clinically used as a specific index in the diagnosis of OP (15).

Previous research has demonstrated the important role of nuclear factor erythrocyte 2-related factor $2 /$ heme oxygenase-1 (Nrf2/HO1) signaling in high glucose-induced osteoblast injury (16). Nrf2 is a regulatory and transcription factor that produces cellular resistance to oxygen-derived free radicals, binds to antioxidant response elements and acts as a sensor for oxidative and electrophilic stress. In addition, $\mathrm{Nrf} 2$ has a protective function against oxidative damage in combination with other antioxidant enzymes, such as HO-1 (17-19).

The aim of the present study was to elucidate the role of E2 in the development of HG-induced OP and provide a theoretical foundation for the treatment of OP. 


\section{Materials and methods}

Cells and drugs. Mouse pre-osteoblast cell line MC3T3-E1 was purchased from American Type Culture Collection. E2 was obtained from Sigma-Aldrich (cat. no. E4260; HPLC $>98 \%$; Merck KGaA). Transfection reagent Lipofectamine ${ }^{\circledR} 3000$ was purchased from Invitrogen (Thermo Fisher Scientific, Inc.). Cell Counting Kit-8 (CCK-8) was obtained from Nanjing Jiancheng Bioengineering Institute.

Cell culture and transfection. MC3T3-E1 cells $\left(1 \times 10^{6}\right.$ cells $/ \mathrm{ml}, 24$-well plates) were cultured in a-minimum essential medium ( $\alpha$-MEM; Gibco; Thermo Fisher Scientific, Inc.) containing 10\% FBS (Gibco; Thermo Fisher Scientific, Inc.), $1 \%$ antibiotics $(100 \mu \mathrm{g} / \mathrm{ml}$ streptomycin and $100 \mathrm{U} / \mathrm{ml}$ penicillin) at $37^{\circ} \mathrm{C}$ in a humidified atmosphere with $5 \% \mathrm{CO}_{2}$. Lipofectamine ${ }^{\circledR} 3000$ was used following the manufacturer's protocol. Briefly, $2 \mu \mathrm{l}$ Lipofectamine ${ }^{\circledR} 3000$ and 40 pmol of small interfering (si)RNA targeting Nrf2 (5'-GAGUAU GAGCUGGAAAAACUU-3') or negative control siRNA (siNC; 5'-GACGAGCGGCACGUGCACAUU-3') (Shanghai GenePharma Co., Ltd.) were mixed in $50 \mu 1$ serum-free medium and incubated at room temperature for $15 \mathrm{~min}$. The lipid compounds were diluted in $300 \mu 1$ serum-free medium and $600 \mu \mathrm{l}$ medium containing FBS, added to the cells and incubated at $37^{\circ} \mathrm{C}$ with $5 \% \mathrm{CO}_{2}$ for $24 \mathrm{~h}$. Following transfection for $24 \mathrm{~h}$, cells were harvested and used for subsequent experiments.

Cell treatments and groups. Different concentrations $(0,10$, $50,100,200$ and $300 \mathrm{mg} / \mathrm{dl}$ ) of glucose were added to the medium and used to treat MC3T3-E1 cells to test viability and to determine the optimal glucose concentration for further experiments. The cells were incubated at $37^{\circ} \mathrm{C}$ with $5 \% \mathrm{CO}_{2}$ for $96 \mathrm{~h}$. Then, the cell viability of the cells treated with the optimal glucose concentration for 1, 3,5 and 7 days was determined. MC3T3-E1 cells were treated with 1, $10 \mathrm{nM}, 0.1$ and $1 \mu \mathrm{M}$ E2 to test cell viability and to select an appropriate dose for further experiments (20). In subsequent experiments, cells were divided into the following groups: i) Control, cells were added to normal medium; ii) HG, cells treated with $200 \mathrm{mg} / \mathrm{dl} \mathrm{HG}$; iii) E2, cells treated with $0.1 \mu \mathrm{M}$ E2; iv) siNrf2, cells transfected with siNrf2; v) NC, cells transfected with siNC; vi) $\mathrm{HG}+\mathrm{E} 2$, cells co-treated with $200 \mathrm{mg} / \mathrm{dl} \mathrm{HG}$ and $0.1 \mu \mathrm{M} \mathrm{E} 2$; vii) $\mathrm{E} 2+$ siNrf2, cells were co-treated with $0.1 \mu \mathrm{M}$ E2 and siNrf2; viii) $\mathrm{HG}+\mathrm{E} 2+$ siNC, cells co-treated with $200 \mathrm{mg} / \mathrm{dl} \mathrm{HG}, 0.1 \mu \mathrm{M} \mathrm{E} 2$ and siNC; ix) $\mathrm{HG}+\mathrm{E} 2+$ siNrf2, cells co-treated with $200 \mathrm{mg} / \mathrm{dl} \mathrm{HG}$, $0.1 \mu \mathrm{M} \mathrm{E} 2$ and siNrf2.

Cell viability assay. Cell viability was detected by CCK- 8 assay according to the manufacturer's protocol. A total of $10 \mu 1$ of CCK-8 solution was added to MC3T3-E1 cells $\left(3 \times 10^{3}\right.$ cells/well) and the cells were incubated at $37^{\circ} \mathrm{C}$ for $2 \mathrm{~h}$ in the dark with $5 \% \mathrm{CO}_{2}$. Subsequently, the optical density of each well at $450 \mathrm{~nm}$ was determined by a microplate reader (Bio-Rad Laboratories, Inc.).

Western blotting. Treated MC3T3-E1 cells $\left(2 \times 10^{4}\right.$ cells/well in 6-well plates) were washed twice with PBS, lysed with
RIPA buffer (Cell Signaling Technology, Inc.) for $2 \mathrm{~h}$ on ice, and centrifuged at $12,000 \mathrm{x} \mathrm{g}$ for $30 \mathrm{~min}$ at $4^{\circ} \mathrm{C}$. Subsequently, supernatant was collected. The nuclear and cytoplasmic extracts were prepared using an NE-PER Nuclear and Cytoplasmic Extraction Reagents kit (Pierce; Thermo Fisher Scientific, Inc.) according to the manufacturer's directions. The protein concentration was determined using the BCA protein kit (Bio-Rad Laboratories, Inc.) and adjusted to a concentration of $5 \mu \mathrm{g} / \mu 1$ using $1 \mathrm{X}$ loading buffer and diethyl pyrocarbonate (DEPC)-treated water. Proteins (at least $30 \mu \mathrm{g} / \mathrm{lane}$ ) were separated by $10 \%$ SDS-PAGE, transferred to a PVDF membrane (Bio-Rad Laboratories, Inc.), blocked with 5\% non-fat milk at room temperature for $2 \mathrm{~h}$ and washed with PBS three times for $5 \mathrm{~min}$. The membranes were then incubated overnight at $4^{\circ} \mathrm{C}$ with the corresponding primary antibody, washed with PBS three times for 15 min, incubated with horseradish peroxidase-conjugated goat anti-mouse or goat anti-rabbit immunoglobulin G secondary antibody $(1: 2,000$; cat. nos. sc-2005 and sc-2004; Santa Cruz Biotechnology, Inc.) for $2 \mathrm{~h}$ at room temperature, washed with PBS three times for $15 \mathrm{~min}$, and washed with PBS + 0.1\% Tween-20 for $15 \mathrm{~min}$. Development was carried out using the EZ-ECL developer kit (Biological Industries), densitometric analysis was performed using Image J 5.0 (National Institutes of Health). The antibodies used in the present study were as follows: Rabbit anti- $\beta$-actin (1:1,000; cat. no. LS-B1625; LifeSpan BioSciences, Inc.), mouse anti-Lamin B1 (1:1,000; cat. no. LS-B6062; LifeSpan BioSciences, Inc.), rabbit anti-Nrf2 (1:1,000; cat. no. ab62352; Abcam) and mouse anti-HO1 (1:1,000; cat. no. ab13248; Abcam). The detection method for nuclear Nrf2 protein was the same as for the other genes mentioned above, and the Lamin B1 was used an internal reference.

$R N A$ isolation and reverse-transcription quantitative $P C R(R T-q P C R)$. Total RNA was extracted from treated MC3T3-E1 cells $\left(2 \times 10^{5}\right.$ cells $)$ using TRIzol reagent ( $1 \mathrm{ml} /$ well; Invitrogen; Thermo Fisher Scientific, Inc.). The lysate was transferred to $1.5 \mathrm{ml}$ Eppendorf tubes and kept at room temperature for $5 \mathrm{~min}$; subsequently $200 \mu 1$ chloroform was added to each tube and inverted for $15 \mathrm{sec}$. Following emulsification, the tubes were left in room temperature for $5 \mathrm{~min}$, centrifuged at $12,000 \mathrm{x} \mathrm{g}$ at $4^{\circ} \mathrm{C}$ for $15 \mathrm{mins}$, and the upper aqueous phase was pipetted into new $1.5 \mathrm{ml}$ tubes with an equal volume of isopropanol $(\sim 400 \mu 1)$; the tubes were kept at room temperature for $10 \mathrm{~min}$. Following another centrifugation at $12,000 \mathrm{x}$ g at $4^{\circ} \mathrm{C}$ for $15 \mathrm{~min}$, the supernatant was discarded and $1 \mathrm{ml}$ of pre-cooled $75 \%$ ice ethanol was added. The tubes were centrifuged at 7,500 $\mathrm{x} \mathrm{g}$ at $4^{\circ} \mathrm{C}$ for $10 \mathrm{~min}$, and the supernatant was discarded. DEPC-treated water $(20 \mu \mathrm{l})$ was added to the tubes to dissolve the RNA. The purity and concentration of RNA was tested using the NanoDrop ND-1000 spectrophotometer (NanoDrop Technologies; Thermo Fisher Scientific, Inc.) at 260/280 nm. RevertAid First Strand cDNA Synthesis kit (Thermo Fisher Scientific, Inc.) was used according to the manufacturer's protocol to reverse transcribe $1 \mu \mathrm{g}$ total RNA to cDNA $\left(42^{\circ} \mathrm{C}\right.$ for $60 \mathrm{~min}$ followed by $70^{\circ} \mathrm{C}$ for 5 min). SYBR Green PCR Master Mix (Roche Diagnostics) 
Table I. Primers for reverse transcription-quantitative PCR.

\begin{tabular}{ll} 
Gene & \multicolumn{1}{c}{ Primer sequence $\left(5^{\prime} \rightarrow 3^{\prime}\right)$} \\
\hline Runx2 & F: AACGATCTGAGATTTGTGGGC \\
& R: CCTGCGTGGGATTTCTTGTT \\
Osteocalcin & F: CTGACCTCACAGATCCCAAGC \\
& R: TGGTCTGATAGCTCGTCACAAG \\
Nrf2 & F: AAACCAGTGGATCTGCCAAC \\
& R: ACGTAGCCGAAGAAACCTCA \\
HO1 & F: TCTCCGATGGGTCCTTACACTC \\
& R: GGCATAAAGCCCTACAGCAACT \\
GAPDH & F: ACTTTGGTATCGTGGAAGGACTCAT \\
& R: GTTTTCTAGACGGCAGGTCAGG \\
\hline
\end{tabular}

F, forward; HO1, heme oxygenase-1; Nrf2, nuclear factor E2-related factor 2; R, reverse; Runx2, Runt-related transcription factor 2.

was used to perform qPCR using ABI 7500 Real-Time PCR Detection System (Thermo Fisher Scientific, Inc.). The PCR cycle was as follows: Initial denaturation at $95^{\circ} \mathrm{C}$ for $10 \mathrm{~min}$, followed by 40 cycles of $94^{\circ} \mathrm{C}$ for $15 \mathrm{sec}$ and $60^{\circ} \mathrm{C}$ for $1 \mathrm{~min}$; final extension at $60^{\circ} \mathrm{C}$ for $1 \mathrm{~min}$. Relative mRNA quantity was determined using the $2^{-\Delta \Delta C q}$ method (21) and normalized to the internal reference gene GAPDH. The primer sequences used for RT-qPCR analysis are presented in Table I.

Apoptosis assay. Treated MC3T3-E1 cells $\left(1.3 \times 10^{5}\right.$ cells/well $)$ were seeded in six-well plates. Supernatant was collected in a $15 \mathrm{ml}$ centrifuge tube, and the culture flask was washed once with $2 \mathrm{ml}$ PBS. The cells were digested with $1 \mathrm{ml}$ trypsin without EDTA and gently shaken. The mixture was kept at room temperature for $1 \mathrm{~min}$, and $\alpha$-MEM containing 10\% FBS was added to terminate the digestion. The cells were centrifuged at $1,000 \mathrm{x}$ g for $3 \mathrm{~min}$ and the supernatant was removed. The cells were washed twice with pre-cooled PBS and resuspended in $1 \mathrm{X}$ Annexin V binding buffer. Annexin-V-FITC Cell Apoptosis Detection kit (cat. no. K201-100; BioVision, Inc.) was used according to the manufacturer's protocol. Briefly, cells were collected and stained with Annexin V-FITC and propidium iodide (PI) at room temperature for $15 \mathrm{~min}$ and counted by flow

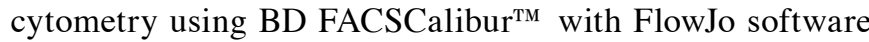
(version 10.0; BD Biosciences). Flow cytometry scatter diagrams demonstrate living cells in the lower left quadrant, necrotic cells in the upper left quadrant, advanced apoptotic cells in the upper right quadrant and early apoptotic cells in the lower right quadrant. The apoptosis rate of total apoptotic cells (early + advanced) was calculated.

Statistical analysis. All data were analyzed using GraphPad Prism 6 software (GraphPad Software, Inc.). All data are expressed as mean \pm SEM. Comparisons of multiple groups were performed by analysis of variance between groups followed by Dunnett's test. $\mathrm{P}<0.05$ was considered to indicate a statistically significant difference.

\section{Results}

Cell viability is decreased by $H G$. CCK-8 assay was used to detect cell viability of MC3T3-E1 cells treated with various concentrations of glucose for $96 \mathrm{~h}$, which revealed that high concentrations of glucose decreased cell viability compared with cells cultured in medium with normal glucose levels (Fig. 1A). Therefore, $200 \mathrm{mg} / \mathrm{dl}$ glucose was selected for subsequent experiments. In addition, cell viability was inhibited by $200 \mathrm{mg} / \mathrm{dl}$ glucose on treatment days 3,5 and 7 compared with control (0 mg/dl) (Fig. 1B).

E2 relieves $H G$-induced osteoblast injury. Cell viability was tested in MC3T3-E1 cells by CCK-8 assay using a range of concentrations of E2. Cell viability was significantly increased by $\mathrm{E} 2$ at $0.1 \mu \mathrm{M}$ (Fig. 2A); thus, $0.1 \mu \mathrm{M} \mathrm{E} 2$ was used for subsequent experiments. To investigate the effect of E2 on HG-induced osteoblast injury, cell viability, osteoblast differentiation markers osteocalcin and Runx2, and Nrf2 and HO1 expression levels were determined following co-incubation with E2 and HG. The results demonstrated that compared with the HG-only group, cell viability was increased (Fig. 2B), osteocalcin and Runx 2 mRNA expression levels were increased (Fig. 2C) in the HG + E2 group. The mRNA expression level of $\mathrm{HO} 1$ in the $\mathrm{HG}+\mathrm{E} 2$ group was significantly higher than that in HG-only group, and there was no significant difference in Nrf2 mRNA expression in control group, HG group, HG+E2 group and E2 group (Fig. 2D). The protein levels of nuclear Nrf2 and downstream target effector HO1 were increased (Fig. 2E-G) in the HG + E2 group compared with the HG-only group.

Protective effect of E2 on HG-induced osteoblast injury is Nrf2-dependent. Markers of osteoblast differentiation were examined to detect changes in cell differentiation following HG, E2 and siNrf2 treatment. Nrf2 was effectively downregulated by siRNA transfection (Fig. 3A). Following Nrf2 silencing, mRNA expression levels of osteocalcin, Runx2, $\mathrm{Nrf} 2$ and $\mathrm{HO} 1$ were significantly reduced, which was reversed by E2; HG treatment significantly reduced the mRNA expression of osteocalcin, Runx2 and HO1; E2 treatment alleviated the inhibitory effect of HG on the mRNA expression of osteocalcin, Runx2, Nrf2 and HO1, while Nrf2 silencing reversed this protective effect of E2, excepting the expression of Runx2 (Fig. 3B-E).

Protein expression levels of $\mathrm{Nrf} 2$ and $\mathrm{HOI}$ are decreased by siNrf2. Western blotting was used to identify the protein expression levels of Nrf2 and HO1. siNrf2 reduced the protein expression of Nrf2 and $\mathrm{HO} 1$ and the Nrf2 and HO1 protein levels in E2 + siNrf2 group were significantly lower than those in E2 group; E2 treatment alleviated the inhibitory effect of $\mathrm{HG}$ on the protein expression of Nrf2 and HO1, while Nrf2 silencing reversed this protective effect of E2 (Fig. 4).

Effects of E2 on HG-induced cell viability and apoptosis were reversed by siNrf2. MC3T3-E1 cell viability and apoptotic rates were examined by CCK-8 assay and flow cytometry, respectively. SiNrf2 treatment alone, E2 treatment alone, 

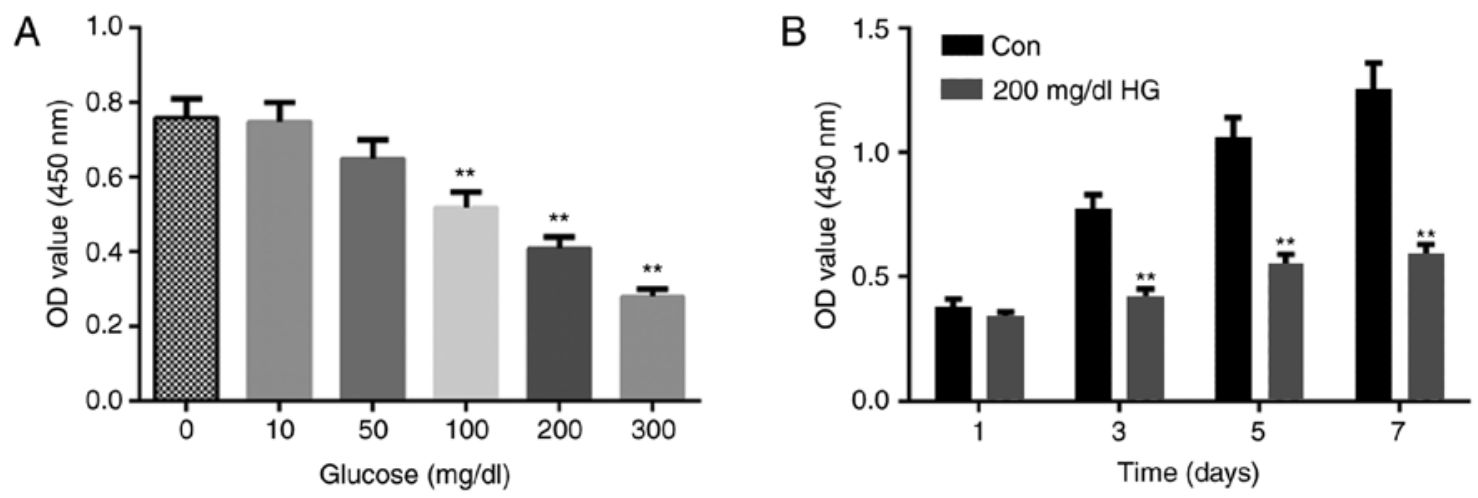

Figure 1. High concentrations of glucose decrease MC3T3-E1 cell viability. (A and B) Cell Counting Kit-8 was used to detect viability of cells treated with (A) different concentrations of glucose or (B) with $200 \mathrm{mg} / \mathrm{dl}$ glucose for 1,3, 5 and 7 days. ${ }^{* *} \mathrm{P}<0.01 \mathrm{vs.} 0 \mathrm{mg} / \mathrm{dl}$ additional glucose (normal glucose). HG, high glucose; OD, optical density.

A

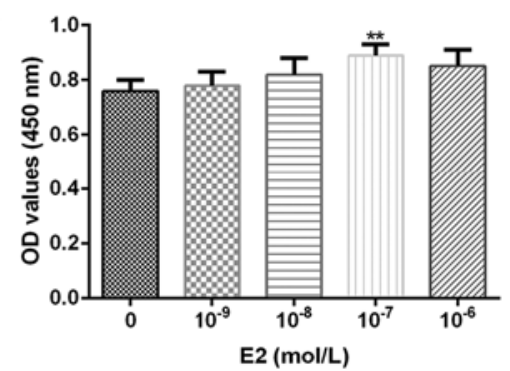

B

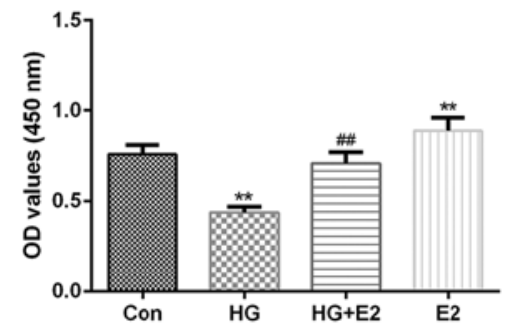

$\mathbf{E}$

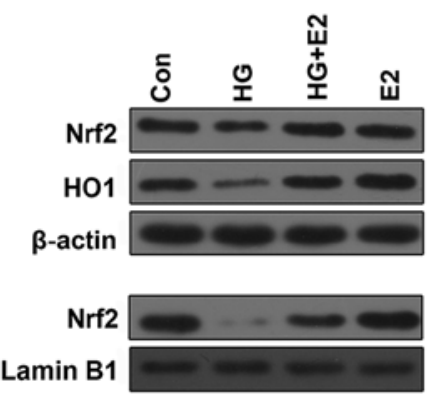

C

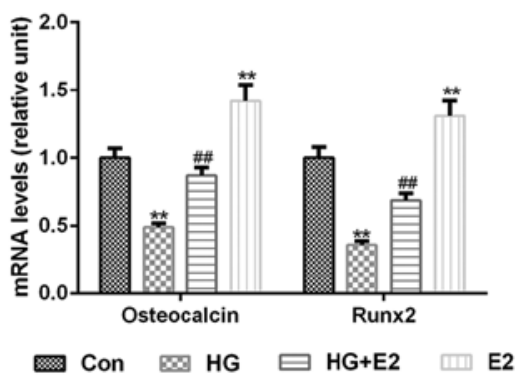

$\mathbf{F}$

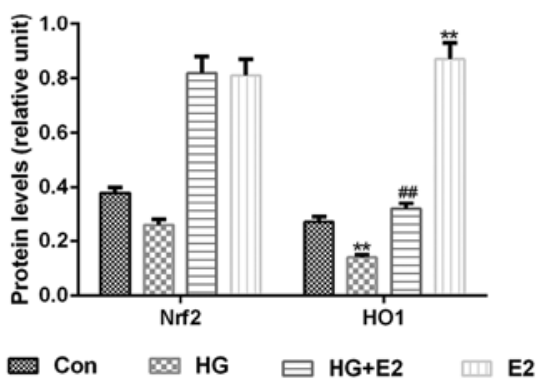

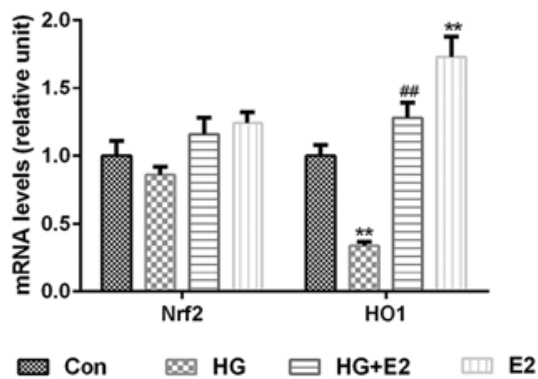

G

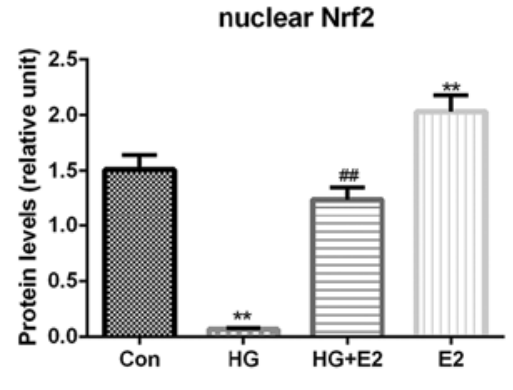

Figure 2. HG-induced osteoblast injury is reversed by E2. (A) CCK-8 was used to detect cell viability in MC3T3-E1 cells treated with different concentrations of E2. (B) Viability of MC3T3-E1 cells treated with HG, E2 or HG + E2 was detected by CCK-8 assay. (C) RT-qPCR was used to determine the mRNA expression levels of osteocalcin and Runx2. (D-G) Nrf2, nuclear Nrf2 and downstream target effector HO1 protein expression levels were determined by western blotting. The relative levels of proteins were calculated using $\beta$-actin or Lamin $\mathrm{B} 1$ for normalization. ${ }^{* *} \mathrm{P}<0.01$ vs. control; ${ }^{\# \#} \mathrm{P}<0.01$ vs. HG-only. CCK-8, Cell Counting Kit-8; Con, control; E2, estradiol; HG, high glucose; HO1, heme oxygenase-1; Nrf2, nuclear factor E2-related factor 2; OD, optical density; RT-qPCR, reverse transcription-quantitative PCR; Runx2, Runt-related transcription factor 2.

and siNrf2 and E2 co-treatment had no significant effect on cell viability, although the cell viability was inhibited in the HG group; E2 treatment effectively enhanced cell viability in HG-treated cells, which was inhibited by cotreatment with siNrf2 (Fig. 5A). Additionally, SiNrf2 treatment alone, E2 treatment alone, and siNrf2 and E2 co-treatment had no significant effect on cell apoptosis, although the apoptosis rate was promoted in the HG group. The apoptotic rate was 

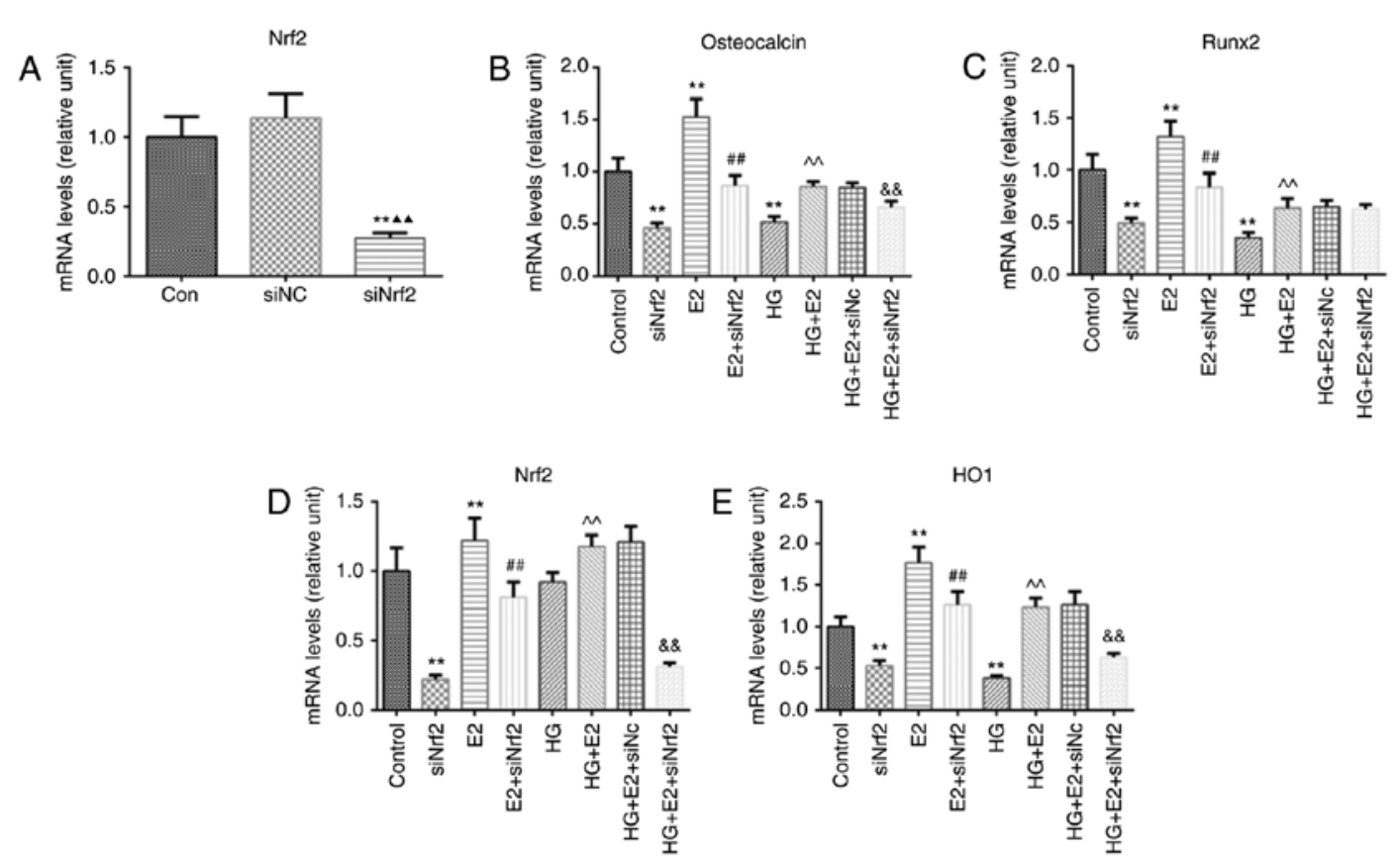

Figure 3. Protective effect of E2 on HG-induced osteoblast injury is Nrf2-dependent. (A) RT-qPCR was used to evaluate the transfection efficiency of siNrf2. (B-E) mRNA expression levels of (B) osteocalcin, (C) Runx2, (D) Nrf2 and (E) HO1 were identified by RT-qPCR in untransfected MC3T3-E1 cells and MC3T3-E1 cells transfected with siNrf2 or siNC and co-treated with $\mathrm{HG}$ and/or E2. ${ }^{* *} \mathrm{P}<0.01$ vs. control; ${ }^{\wedge \boldsymbol{\Lambda}} \mathrm{P}<0.01$ vs. siNC; ${ }^{\# /} \mathrm{P}<0.01$ vs. E2; ${ }^{\wedge} \mathrm{P}<0.01$ vs. HG; \&\&P<0.01 vs. HG + E2. Con, control; E2, estradiol; HG, high glucose; HO1, heme oxygenase-1; NC, negative control; Nrf2, nuclear factor E2-related factor 2; OD, optical density; RT-qPCR, reverse transcription-quantitative PCR; Runx2, Runt-related transcription factor 2; si, small interfering RNA.

A

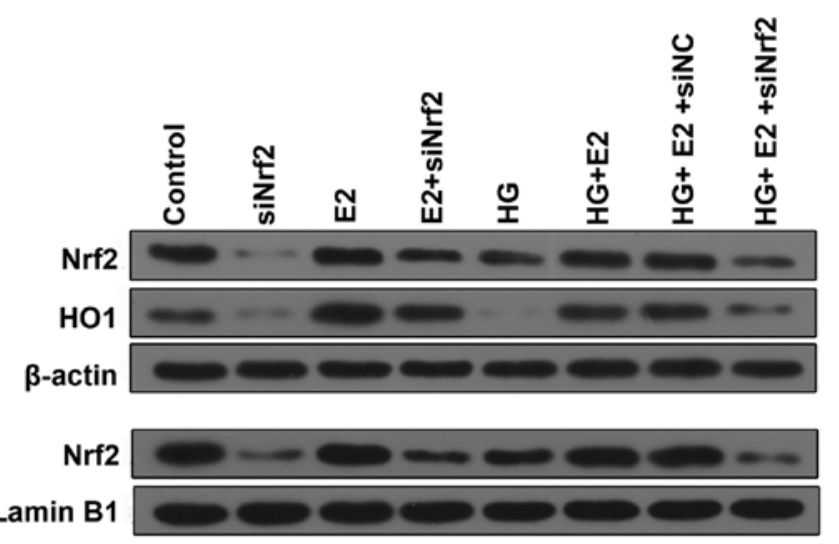

B

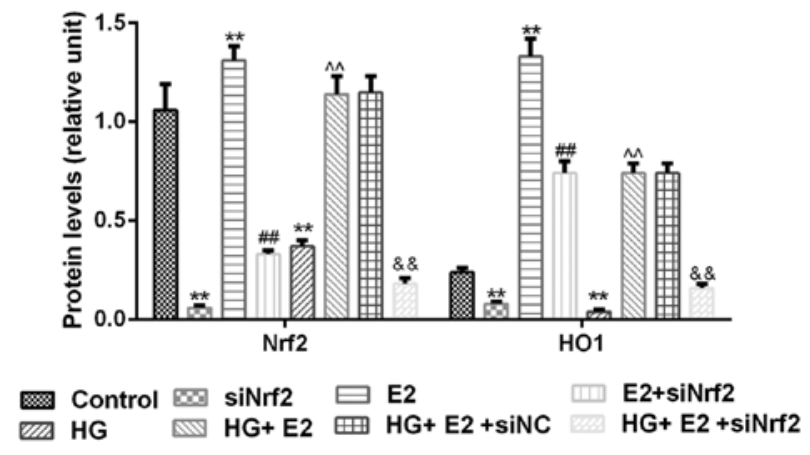

C

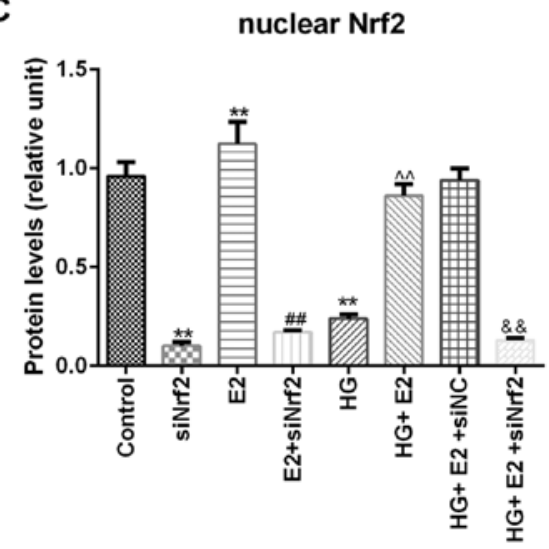

Figure 4. Protein expression levels of Nrf2 and $\mathrm{HO} 1$ are decreased by siNrf2. (A) Western blotting was used to determine the protein expression levels of Nrf2 and $\mathrm{HO} 1$ in untransfected MC3T3-E1 cells and MC3T3-E1 cells transfected with siNrf2 or siNC and co-treated with HG and/or E2. (B and C) The relative protein expression levels from (A) calculated using $\beta$-actin or Lamin $\mathrm{B} 1$ for normalization. ${ }^{* *} \mathrm{P}<0.01$ vs. control; ${ }^{\# \#} \mathrm{P}<0.01$ vs. $\mathrm{E} 2$; ${ }^{\wedge} \mathrm{P}<0.01 \mathrm{vs}$. HG-only; ${ }_{\&}^{\&} \mathrm{P}<0.01$ vs. HG + E2. E2, estradiol; HG, high glucose; HO1, heme oxygenase-1; Nrf2, nuclear factor E2-related factor 2; siNC, negative control small interfering RNA; siNrf2, small interfering RNA targeting Nrf2. 

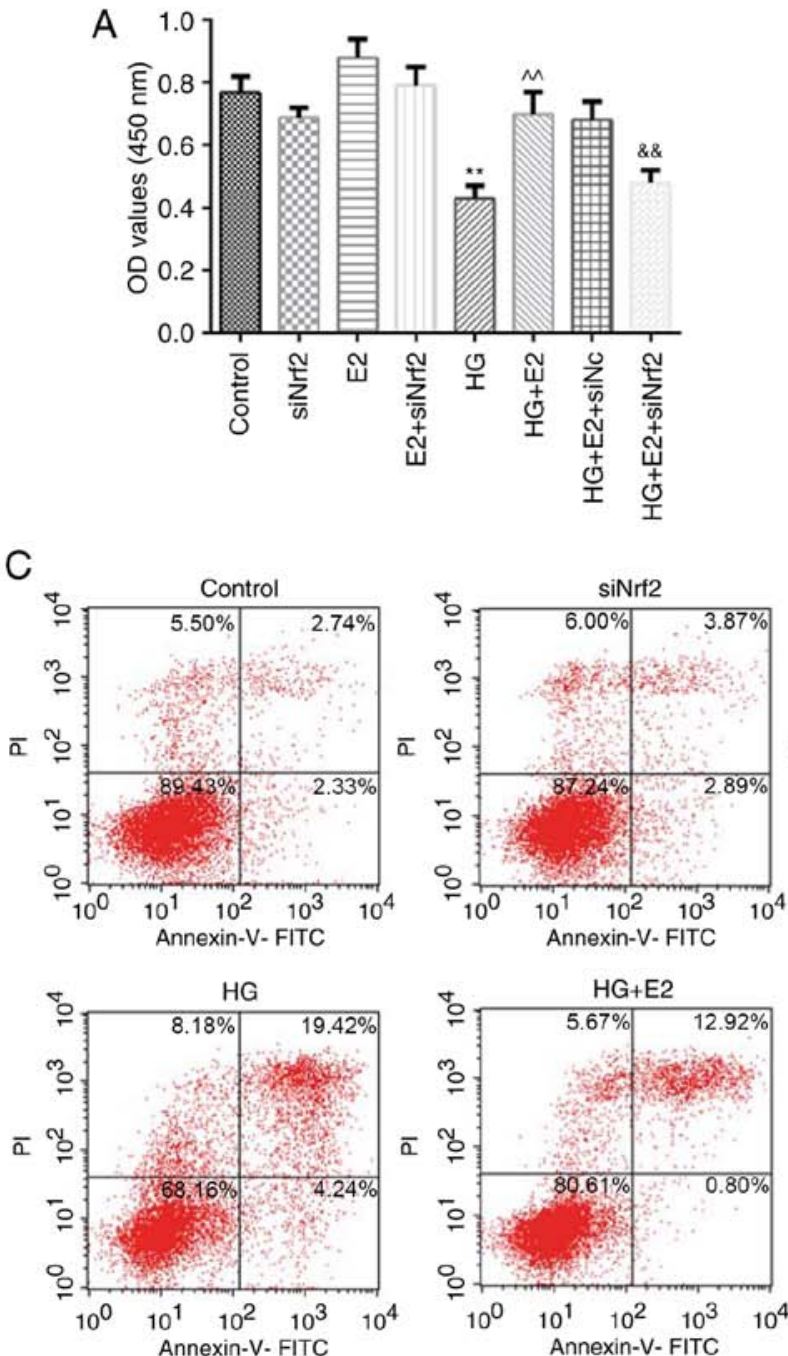
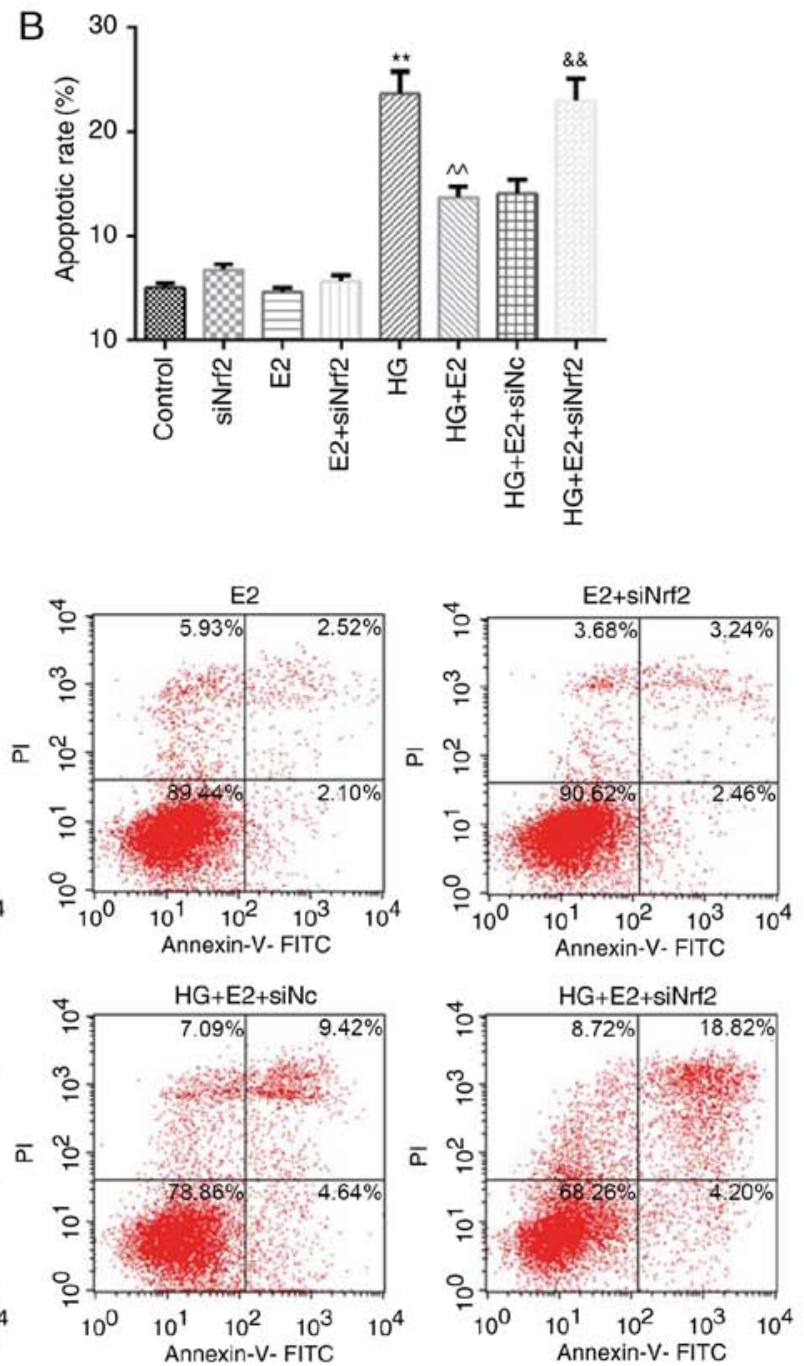

Figure 5. Effects of E2 on MC3T3-E1 cell viability and apoptosis are reversed by siNrf2. (A) Cell Counting Kit-8 assay was used to detect viability in untransfected MC3T3-E1 cells and MC3T3-E1 cells transfected with siNrf2 or siNC and co-treated with HG and/or E2. (B and C) Apoptotic rates were tested by flow cytometry. ${ }^{* *} \mathrm{P}<0.01$ vs. control; ^^P<0.01 vs. HG-only; \&\& $\mathrm{P}<0.01$ vs. HG + E2. E2, estradiol; HG, high glucose; Nrf2, nuclear factor E2-related factor 2; siNC, negative control small interfering RNA; siNrf2, small interfering RNA targeting Nrf2.

significantly lower in the $\mathrm{HG}+\mathrm{E} 2$ group compared with the HG-only group, whereas cells in the HG + E2 + siNrf2 group exhibited a higher apoptotic rate compared with the $\mathrm{HG}+\mathrm{E} 2+\operatorname{siNC}$ group (Fig. 5B and C).

\section{Discussion}

Hyperglycemia is one of the possible causes for OP and fracture in diabetes (22). OP is characterized by reduced bone mass, alterations in the microarchitecture of bone tissue, reduced bone strength, and an increased risk of fracture (23). A previous study has demonstrated that bone mass in diabetic patients is significantly decreased, and the risk of fracture is increased (24). Estrogen reduction significantly increases the risk of OP $(25,26)$. E2 the most potent estrogen; however, its role in diabetes-related OP is poorly understood.

To explore the mechanism of diabetes-related OP, mouse pre-osteoblast MC3T3-E1 cells were treated with high concentrations of glucose to simulate diabetes-induced OP. The results of CCK-8 experiments demonstrated that the cell viability was significantly reduced by $\mathrm{HG}$ on treatment days 3 , 5 and 7 . These data suggested that HG may contribute to bone damage.

Previous studies have demonstrated that postmenopausal bone turnover rate is reduced, and E2 serves an important role in the development of OP (27-29). Gopalakrishnan et al revealed that insulin and E2 increased the number of mineralized nodules, the area stained for collagen and mineralization, as well as the proliferation of rat bone marrow stromal cells under HG (30). Estrogen-induced transforming growth factor $\beta$ receptor 1 and bone morphogenetic protein receptor type $1 \mathrm{~A}$ expression levels were suppressed by estrogen receptor $\beta$ activation in MC3T3-E1 cells (31). The present study demonstrated that E2 may serve an important protective role in HG-induced osteogenic injury. Different concentrations of E2 were added to mouse osteoblasts, and the results revealed that $0.1 \mu \mathrm{M} \mathrm{E} 2$ significantly increased MC3T3-E1 cell viability. This result was consistent with the study of He et al (31) that high concentration of E2 can improve the cell viability of MC3T3-E1.

Runx 2 and osteocalcin are essential for promoting osteoblast differentiation in the early stage of induction (32). A 
previous study demonstrated that bone cements exhibit osteoinductive activity, based on the results of elevated expression levels of genes encoding for osteocalcin and Runx2 in both undifferentiated and differentiated MC3T3-E1 cells (33). Low expression of Nrf2 and HO-1 in osteoblast injury has also been demonstrated (34). HO-1 inhibits osteoclastogenesis and bone destruction in an arthritis model (35) and upregulates osteogenic differentiation in human periodontal ligament cells (36). Recent studies have indicated that HO-1 expression is mediated by Nrf2 activation in MC3T3-E1 cells $(37,38)$. In the present study, HG treatment decreased cell viability and reduced osteocalcin, Runx2, HO1 and nuclear Nrf2 expression levels; these changes were reversed by E2. To verify whether the protective effect of E2 was related to Nrf2, siRNA silencing was used to downregulate Nrf2. Expression levels of osteocalcin, HO1 and nuclearNrf2 were upregulated by E2 compared with control cells under HG-induced osteogenic injury; however, these effects were reversed by siNrf2, with the exception of Runx2. It is possible that not all tested osteogenic genes were involved in the effect of Nrf2 on osteoblast injury. The results of the present study suggested that E2 may effectively protect osteoblasts from damage, and this protection may rely on the expression of Nrf2.

Severe apoptosis can be observed in certain disease conditions, including diabetes (39). By regulating the balance between cell growth and death, apoptosis serves a key role in maintaining homeostasis $(40,41)$. Therefore, targeting apoptosis has become a common therapeutic method for diabetes-induced bone damage (42). In the present study, the results of the apoptosis assay by flow cytometry demonstrated that silencing Nrf2 effectively reversed the inhibitory effect of E2 on HG-induced apoptosis. Therefore, E2 may protect osteoblasts against injury through a Nrf2-dependent mechanism. However, the potential role of E2 in diabetes-related OP remains unclear, and the involvement of other signaling pathways involved in the regulation of diabetes-related OP by E2 should be further investigated.

There are certain limitations to the present study. Firstly, the functions of E2 on HG-treated MC3T3-E1 cells were only supported by in vitro experiments. Secondly, alkaline phosphatase is a typical marker in the early stage of osteogenic differentiation and its level requires further examination. Additionally, the expression levels of estrogen receptor in differentiated-MC3T3-E1 need to be quantified.

In the present study, mouse pre-osteoblast MC3T3-E1 cell was used to set up a model of diabetes-induced OP, which was induced by HG. E2 treatment resulted in increases in cell viability, expression levels of osteoblast genes osteocalcin and Runx2, as well as increased expressions of HO1 and nuclear Nrf2. These changes were reversed by Nrf2 silencing, with the exception of Runx2. Additionally, following Nrf2 silencing, cell apoptosis was significantly increased in HG-treated cells. Thus, E2 may prevent HG-induced osteoblast injury by activating Nrf2/HO1 signaling pathways, E2 may be a potential drug for the treatment of diabetes-related OP.

\section{Acknowledgements}

Not applicable.

\section{Funding}

No funding was received.

\section{Availability of data and materials}

The datasets generated and analyzed during the study are available from the corresponding author on reasonable request.

\section{Authors' contributions}

Substantial contributions to conception and design: GL, XJ. Data acquisition, data analysis and interpretation: LL, XL, HL, ZZ. Drafting the article or critically revising it for important intellectual content: GL, XJ. All authors read and approved the manuscript and agree to be accountable for all aspects of the research in ensuring that the accuracy or integrity of any part of the work are appropriately investigated and resolved.

\section{Ethics approval and consent to participate}

Not applicable.

\section{Patient consent for publication}

Not applicable.

\section{Competing interests}

The authors declare that they have no competing interests.

\section{References}

1. Xu Y, Wang L, He J, Bi Y, Li M, Wang T, Wang L, Jiang Y, Dai M, Lu J, et al: Prevalence and control of diabetes in Chinese adults. JAMA 310: 948-959, 2013.

2. Yan P, Zhang Z, Wan Q, Zhu J, Li H, Gao C, Ma H and Xu Y: Association of serum uric acid with bone mineral density and clinical fractures in Chinese type 2 diabetes mellitus patients: A cross-sectional study. Clin Chim Acta 486: 76-85, 2018.

3. Chen JS, Yang A and Murrell DF: Prevalence and pathogenesis of osteopenia and osteoporosis in epidermolysis bullosa: An evidence based review. Exp Dermatol: Aug 17, 2018 (Epub ahead of print). doi: 10.1111/exd.13771.

4. Schousboe JT: Vertebral fracture identification as part of a comprehensive risk assessment in patients with osteoporosis. Curr Osteoporos Rep 16: 573-583, 2018.

5. Crandall CJ: Risk assessment tools for osteoporosis screening in postmenopausal women: A systematic review. Curr Osteoporos Rep 13: 287-301, 2015.

6. Eastell R, O'Neill TW, Hofbauer LC, Langdahl B, Reid IR, Gold DT and Cummings SR: Postmenopausal osteoporosis. Nat Rev Dis Primers 2: 16069, 2016.

7. Baker ME and Lathe R: The promiscuous estrogen receptor: Evolution of physiological estrogens and response to phytochemicals and endocrine disruptors. J Steroid Biochem Mol Biol 184: 29-37, 2018

8. Mathis KM, Sturgeon KM, Winkels RM, Wiskemann J, De Souza MJ and Schmitz KH: Bone resorption and bone metastasis risk. Med Hypotheses 118: 36-41, 2018.

9. Huang X, Lv Y, He P, Wang Z, Xiong F, He L, Zheng X, Zhang D, Cao Q and Tang C: HDL impairs osteoclastogenesis and induces osteoclast apoptosis via upregulation of ABCG1 expression. Acta Biochim Biophys Sin (Shanghai) 50: 853-861, 2018.

10. Wang Y, Luo TB, Liu L and Cui ZQ: LncRNA LINC00311 promotes the proliferation and differentiation of osteoclasts in osteoporotic rats through the notch signaling pathway by targeting DLL3. Cell Physiol Biochem 47: 2291-2306, 2018. 
11. Tantikanlayaporn D, Tourkova IL, Larrouture Q, Luo J, Piyachaturawat $\mathrm{P}$, Witt MR, Blair $\mathrm{HC}$ and Robinson LJ: Sphingosine-1-phosphate modulates the effect of estrogen in human osteoblasts. JBMR Plus 2: 217-226, 2018.

12. Valenti MT, Dalle Carbonare L and Mottes M: Ectopic expression of the osteogenic master gene RUNX2 in melanoma. World J Stem Cells 10: 78-81, 2018.

13. Kanazawa I, Tanaka S and Sugimoto T: The association between osteocalcin and chronic inflammation in patients with type 2 diabetes mellitus. Calcif Tissue Int 103: 599-605, 2018.

14. Wu CC, Wang CC, Lu DH, Hsu LH, Yang KC and Lin FH: Calcium phosphate cement delivering zoledronate decreases bone turnover rate and restores bone architecture in ovariectomized rats. Biomed Mater 7: 035009, 2012.

15. Tanaka S, Miyazaki T, Uemura Y, Kuroda T, Miyakawa N, Nakamura T, Fukunaga M, Ohashi Y, Ohta H, Mori S, et al: Design of a randomized clinical trial of concurrent treatment with vitamin $\mathrm{K} 2$ and risedronate compared to risedronate alone in osteoporotic patients: Japanese Osteoporosis Intervention Trial-03 (JOINT-03). J Bone Miner Metab 32: 298-304, 2014

16. Lin H, Wei B, Li G, Zheng J, Sun J, Chu J, Zeng R and Niu Y: Sulforaphane reverses glucocorticoid-induced apoptosis in osteoblastic cells through regulation of the Nrf2 pathway. Drug Des Devel Ther 8: 973-982, 2014.

17. Vargas MR and Johnson JA: The Nrf2-ARE cytoprotective pathway in astrocytes. Expert Rev Mol Med 11: e17, 2009.

18. Ma Q: Role of nrf2 in oxidative stress and toxicity. Annu Rev Pharmacol Toxicol 53: 401-426, 2013.

19. Dong F, Wang S, Wang Y, Yang X, Jiang J, Wu D, Qu X, Fan H and Yao R: Quercetin ameliorates learning and memory via the Nrf2-ARE signaling pathway in d-galactose-induced neurotoxicity in mice. Biochem Biophys Res Commun 491: 636-641, 2017

20. Shang ZZ, Li X, Sun HQ, Xiao GN, Wang CW and Gong Q: Differentially expressed genes and signalling pathways are involved in mouse osteoblast-like MC3T3-E1 cells exposed to 17- $\beta$ estradiol. Int J Oral Sci 6: 142-149, 2014.

21. Livak KJ and Schmittgen TD: Analysis of relative gene expression data using real-time quantitative PCR and the 2(-Delta Delta C(T)) method. Methods 25: 402-408, 2001

22. You L, Gu W, Chen L, Pan L, Chen J and Peng Y: MiR-378 overexpression attenuates high glucose-suppressed osteogenic differentiation through targeting CASP3 and activating PI3K/Akt signaling pathway. Int J Clin Exp Pathol 7: 7249-7261, 2014.

23. Ralston SH and de Crombrugghe B: Genetic regulation of bone mass and susceptibility to osteoporosis. Genes Dev 20: 2492-2506, 2006

24. Hofbauer LC, Brueck CC, Singh SK and Dobnig H: Osteoporosis in patients with diabetes mellitus. J Bone Miner Res 22: $1317-1328,2007$

25. Cheng YZ, Yang SL, Wang JY, Ye M, Zhuo XY, Wang LT, Chen $\mathrm{H}$, Zhang $\mathrm{H}$ and Yang L: Irbesartan attenuates advanced glycation end products-mediated damage in diabetes-associated osteoporosis through the AGEs/RAGE pathway. Life Sci 205: 184-192, 2018

26. Mederle OA, Balas M, Ioanoviciu SD, Gurban CV, Tudor A and Borza C: Correlations between bone turnover markers, serum magnesium and bone mass density in postmenopausal osteoporosis. Clin Interv Aging 13: 1383-1389, 2018

27. Prior JC: Progesterone for the prevention and treatment of osteoporosis in women. Climacteric 21: 366-374, 2018.

28. Pardhe BD, Pathak S, Bhetwal A, Ghimire S, Shakya S, Khanal PR and Marahatta SB: Effect of age and estrogen on biochemical markers of bone turnover in postmenopausal women: A population-based study from Nepal. Int J Womens Health 9: 781-788, 2017
29. Tian L, Yang R, Wei L, Liu J, Yang Y, Shao F, Ma W, Li T, Wang Y and Guo T: Prevalence of osteoporosis and related lifestyle and metabolic factors of postmenopausal women and elderly men: A cross-sectional study in Gansu province, Northwestern of China. Medicine (Baltimore) 96: e8294, 2017.

30. Gopalakrishnan V, Vignesh RC, Arunakaran J, Aruldhas MM and Srinivasan N: Effects of glucose and its modulation by insulin and estradiol on BMSC differentiation into osteoblastic lineages. Biochem Cell Biol 84: 93-101, 2006.

31. He HL, Liu C, Li BX, Wang CQ, Li HT and Gu L: Estrogen-induced Tgfbrl and Bmprla expression repressed via estrogen receptor beta in MC3T3-E1 cells. Chin Med J (Engl) 131: 2558-2565, 2018.

32. Fan S, Gao X, Chen P and Li X: Myricetin ameliorates glucocorticoid-induced osteoporosis through the ERK signaling pathway. Life Sci 207: 205-211, 2018.

33. Uskoković V, Graziani V, Wu VM, Fadeeva IV, Fomin AS, Presniakov IA, Fosca M, Ortenzi M, Caminiti R and Rau JV: Gold is for the mistress, silver for the maid: Enhanced mechanical properties, osteoinduction and antibacterial activity due to iron doping of tricalcium phosphate bone cements. Mater Sci Eng C Mater Biol Appl 94: 798-810, 2019.

34. Kook SH, Kim KA, Ji H, Lee D and Lee JC: Irradiation inhibits the maturation and mineralization of osteoblasts via the activation of Nrf2/HO-1 pathway. Mol Cell Biochem 410: 255-266, 2015.

35. Zwerina J, Tzima S, Hayer S, Redlich K, Hoffmann O, Hanslik-Schnabel B, Smolen JS, Kollias G and Schett G: Heme oxygenase $1(\mathrm{HO}-1)$ regulates osteoclastogenesis and bone resorption. FASEB J 19: 2011-2013, 2005.

36. Kook YA, Lee SK, Son DH, Kim Y, Kang KH, Cho JH, Kim SC, Kim YS, Lee HJ, Lee SK and Kim EC: Effects of substance P on osteoblastic differentiation and heme oxygenase-1 in human periodontal ligament cells. Cell Biol Int 33: 424-428, 2009.

37. Choi EM, Suh KS, Kim YJ, Hong SM, Park SY and Chon S: Glabridin alleviates the toxic effects of methylglyoxal on osteoblastic MC3T3-E1 cells by increasing expression of the glyoxalase system and $\mathrm{Nrf} 2 / \mathrm{HO}-1$ signaling and protecting mitochondrial function. J Agric Food Chem 64: 226-235, 2016.

38. Han D, Gao J, Gu X, Hengstler JG, Zhang L, Shahid M, Ali T and Han B: P21 $1^{\text {Waf } 1 / \text { Cipl } 1}$ depletion promotes dexamethasone-induced apoptosis in osteoblastic MC3T3-E1 cells by inhibiting the Nrf2/HO-1 pathway. Arch Toxicol 92: 679-692, 2018.

39. Tekula S, Khurana A, Anchi P and Godugu C: Withaferin-A attenuates multiple low doses of Streptozotocin (MLD-STZ) induced type 1 diabetes. Biomed Pharmacother 106: 1428-1440, 2018.

40. Ghiasi SM, Dahllof MS, Osmai Y, Osmai M, Jakobsen KK, Aivazidis A, Tyrberg B, Perruzza L, Prause MCB, Christensen DP, et al: Regulation of the $\beta$-cell inflammasome and contribution to stress-induced cellular dysfunction and apoptosis. Mol Cell Endocrinol 478: 106-114, 2018.

41. Zheng G, Li H, Zhang T, Yang L, Yao S, Chen S, Zheng M, Zhao $\mathrm{Q}$ and Tian $\mathrm{H}$ : Irisin protects macrophages from oxidized low density lipoprotein-induced apoptosis by inhibiting the endoplasmic reticulum stress pathway. Saudi J Biol Sci 25: 849-857, 2018.

42. Zhao W, Zhang WL, Yang B, Sun J and Yang MW: NIPA2 regulates osteoblast function via its effect on apoptosis pathways in type 2 diabetes osteoporosis. Biochem Biophys Res Commun 513: 883-890, 2019.

This work is licensed under a Creative Commons Attribution-NonCommercial-NoDerivatives 4.0 International (CC BY-NC-ND 4.0) License. 